\title{
The changing panorama of interactive storytelling: a review from locative to transmedia
}

\author{
Valentina Nisi*
}

\begin{abstract}
Resumo: Desde os primórdios da civilização que o modo como contamos e consumimos histórias define o sentido que damos ao mundo. Cada nova tecnologia implica um impacto nos artefactos narrativos. Hoje em dia, as tecnologias digitais ubíquas permitem estruturar e distribuir narrativas de modos novos e sem precedentes. Este artigo discue a evolução da narrativa interativa surgida pelo advento de interfaces móveis. Tentarei exemplificar esta evolução a partir do estudo crítico de estudos de casos e ter em conta o meu próprio percurso de investigação.

Palavras-chave: narrativa transmedia; narrativa interativa; meios de comunicação; historias multimedia com localização; tecnologias conscientes do contexto; interação Homem-computador.
\end{abstract}

Resumen: Desde los orígenes de la civilización, el modo como contamos y consumimos historias define el sentido que damos al mundo. Cada nueva tecnología implica un impacto en los artefactos narrativos. Hoy en día, las tecnologías digitales ubicuas permiten estructurar y distribuir narraciones de modos nuevos y sin precedentes. Este artículo presenta la evolución interactiva surgida con el advenimiento de interfaces móviles. Intentaré ejemplificar dicha evolución a partir del análisis crítico de estudios de caso, teniendo en cuenta mi propia trayectoria investigadora.

Palabras clave: narrativa transmedia; narrativa interactiva; medios de comunicación; historias multimedia con ubicación; tecnologías conscientes del contexto; interacción Hombre-computadora.

\begin{abstract}
Since the early days of civilization, the way we tell and consume stories defines how do we make sense of the world. Every new technology has an impact on our narrative artifacts. Nowadays ubiquitous digital technologies allow us to structure and distribute our narratives in novel and unprecedented ways. This paper discusses the evolution of interactive storytelling brought about by the advent of mobile Interfaces. I will exemplify this shift reviewing a series of case studies highlighted from my own research path.

Keywords: transmedia storytelling; interactive narrative; locative media; location aware multimedia stories; context aware technologies; human computer interaction.
\end{abstract}

Résumé : Depuis l'aube de la civilisation, la façon dont nous racontons et consommons les histoires définit le sens que nous donnons au monde. Chaque nouvelle tech-

* University of Madeira, Department of Exact Sciences and Engeneering, Madeira Interactive Technologies Institute. 9020-105, Funchal, Portugal.

E-mail: valentina.nisi@gmail.com 
nologie implique un impact sur les artefacts narratifs. De nos jours, les technologies numériques omniprésentes nous permettent de structurer et de diffuser des récits de manière nouvelle et sans précédent. Cet article traite de l'évolution du récit interactif découlant de l'avènement des interfaces mobiles. Je vais essayer d'illustrer cette évolution à partir de l'étude critique des études de cas et prendre en compte ma propre piste de recherche.

Mots-clés : récit transmédia ; récit interactif ; locatif média ; histoires multimédias avec emplacement ; technologies contextuelles ; interaction homme-machine.

\section{Introduction}

Stories and storytelling are pervasive and ubiquitous. Storytelling is a creative process through which people share and reflect on life experiences, solve problems, or teach lessons. Stories were considered central to society long before humans could read and write and are a fundamental component of human experience (Slaney, 2012; Smith, 2000). They perform a critical function in society, allowing for dialog between people, culture, and time (Madej \& Krystina, 2003). A story has a beginning, a middle, and ending, it is a journey that follows a trajectory, a human life or a hero's journey. A story is told by someone to someone else (Alexander \& Levine, 2008). Today, with digital mobile networked technologies, this pattern is changing. Stories now are open-ended, branching, hyperlinked, cross-media, participatory, exploratory, and unpredictable. Today, narratives flow through games, interactive platforms and many other digital tools available through the internet. Listening to and reading stories has become a dynamic and participatory process, where the lines between the author and the audience are blurred (Spanoudakis, et al., 2015). The trajectory of interactive storytelling followed the pace of digital technologies from hyperlinked cybertexts to transmedia mobile stories. In this article I will outline a possible trajectory of interactive storytelling illustrated through a review of my own research and creative work. This is a personal view of an evolving field which spans many areas of creative work, research and technological development.

\section{Interactive storytelling, a changing panorama}

Storytelling with digital tools dates back to the 90 s, the early days of personal and networked computers (Alexander \& Levine, 2008). Pioneering work on hypertext explored new ways of creating and experiencing narrative, often nonlinear and multi branching. Espen Aarseth calls these kind of narrative "ergodic literature,"from the Greek words for "work"and "path" (Aarseth, 1997). For example, 253, a hypertext novel created by Geoff Ryman in 1996. In this 
novel 253 passengers of the London underground are travelling between Embankment and Elephant and Castel. Each character is introduced by a 253 words text, that gives access to his or her details and thoughts (Ryman, 1996). Each reader has her own experience of the story depending on her journey through the hypertext. The reading experience reflects the preferences in choosing which character to follow and which path to explore within the collection of story fragments proposed by the author. Space, at least as a metaphor, becomes the editing strategy of the narrative text. At the same time, some hyperlinked digital narratives are created offline and then published on the web using HTML or proprietary multimedia formats (e.g. Adobe Flash). During these years, interactive stories explore the use of traditional channels and digital formats such as CDs and DVDs. A successful example of the emerging poetics of interactive narrative (Bizzocchi \& Woodbury, 2003) is the "Cerimony of Innocence" CD-ROM adaptation of Bantock's mystery novel of Griffin and Sabine, dating back 1997.

With the explosive growth of the world wide web in the late 90', storytelling on the internet flourished and with it the online distribution of multimedia rich hypertext. Multimedia and its implications in design and production became object of study and research. Projects like MIT Athena provide examples and latest trends in Multimedia Computing and its potential (Arfman \& Roden, 1992). In the early 2000, mobile devices became ubiquitous, many of them work with GPS modules, enabling location and context aware services. Artists and storytellers are fascinated by the potential of tracing, distributing and crafting stories that inhabit the real world, migrate content fruition from the screen into the real space, treating "the world as a game board" (Falk et al., 2001). Projects such as AmsterdamREALTIME ${ }^{1}$ and the Milk project by Esther Polak become examples of how to creatively subvert the use of GPS technologies by tracing citizens movements through the city or the milk journey from Latvia producers to Netherlands consumers (Polak, 2002). Hyperlinked narrative structures already brought about the importance of the spatial metaphor in constructing narrative texts. With the integration of location awareness in our personal devices, spaces became physical branching structures for the audiences to walk through. The use of mobile technologies as connection interfaces blur the traditional borders between physical and digital spaces (Souza e Silva, 2006). Urban spaces as intertwined fabrics of memories, current visitors and future perceptions, contain rich material for the potential of the new media (Lynch, 1960; Stevens, 2007) and they become the stage of many locative media experiments, from authoring platforms to documentary and fictional

1. http://realtime.waag.org/ 
stories. However, while some efforts are focused on facilitating content creators, such as the locative authoring Urban Tapestries platform (Angus et al., 2008), other works focus on the creation of drama and narrative experiences for the mobile audiences. Examples include many of the prototypes developed and tested within the 'Mobile Bristol' initiative (Cater et al., 2005) and the 'Equator' 2 research project. In Riot 1831 for example (Reid et al., 2005) public reactions to the media scape are collected and distilled in a series of guidelines for designing location-based drama (Cater et al., 2005); (FitzGerald et al., 2013).

As locative media evolves, GPS inaccuracies are often reported as negatively affecting the user experience (Bell et al., 2006); (Crabtree et al., 2004); (Nisi \& Oakley, 2006). Efforts are made into the design ever seamless experiences for the mobile audiences (Chalmers \& Galani, 2004); (Bell et al., 2006). In some cases, GPS is replaced or supported by other means and technologies, such as position self-reporting, RFID tags, Markers, QR codes, iButtons or Beacons (Benford et al., 2003). During the first decade of the new millennium, technology progress enables the tailoring of ever complex and specific experiences for the mobile users (Paay et al., 2008); (Bell et al., 2006). Public spaces are increasingly augmented with layers of information and multimedia content (Zheng et al., 2014). Audiences can participate and generate content that is published in real time. One of the most recent narrative phenomena that make use of this feature is transmedia storytelling. Put simply, transmedia storytelling is a technique that uses current digital technologies to turn stories into immersive, multilayered experiences that can be delivered to a range of different audiences through different media channels. Despite the concept and a definition, transmedia was anticipated by Jenkins back in 2006, thanks to the rapid uptake of mobile networked technologies. Today transmedia takes on a new life used for marketing and promotional tourism campaigns as well as for activism and behavioral change. No matter what the answer is, the storytelling panorama is in continuous flux. New technologies allow new modes of creation and distribution, and artist and engineers have never been better equipped to fuel our imagination constructing imaginary worlds in the same time and space where our lives unfold.

\section{Case studies}

The remainder of this paper explores the changing panorama of interactive storytelling by exemplifying and reflecting on a collection of case studies.

2. www.equator.ac.uk/ 
These projects are selected from the body of my own creative and research work, resulting from many fruitful collaborations from the year 2000 until today at Media Lab Europe in Ireland, Fattoria Mediale in Amsterdam and M-ITI in Madeira. The case studies cover from desktop based site specific hypermedia interactive narratives (Weirdview), which reveals the power of real place, as a real physical site and community (as a connected social networks) in Interactive Narratives structures, to several location-based multimedia projects developed in different cities and cultures that highlight the power of locative media and community to capture a grass root felt atmosphere of the locale. The last case study is a transmedia storytelling ongoing research project (Echoes of Nature) where location aware storytelling merge with participatory web published journalism, opening avenues for future forms of narratives, connecting fiction, science and local history and traditions.

\section{Weird View (2000) - Location and community ties as a narrative journey}

Weird View is a multibranching interactive narrative, resulting from the collaboration with artist and researcher Jo Briggs (Nisi \& Haahr, 2006). Building on the power of hyperlinked structures and oral storytelling. Weird View attempts to capture community folklore and represent it in the form of an interactive, nonlinear narrative. True stories were collected by word of mouth from inhabitants of a row of terraced houses in Dublin, Ireland. The collected anecdotes were then scripted and produced to form a set of narrative audiovisual fragments available through clicking through a desktop based graphical user interface (GUI) representing the row of houses in which the community lived (see Fig. 1). The anecdotes could also be browsed through the social network that linked the inhabitants one another. Short texts supplied the visual fragments. Such texts would succinctly tell the story, name the protagonists and hyperlink their stories. When shown back to the community, the Weird View project resulted in awakening community awareness through re appropriation of local, social and personal stories. Technically, Weird View draws upon storytelling traditions in a number of ways. First, the oral tradition, as stories were collected by word of mouth, casting the community members in the role of storytellers while the authors functioned as the audience. Secondly, when the interactive story was presented to the community, the roles were reversed, i.e., the authored Weird View application played the role of storytellers and the community members became the audience. 


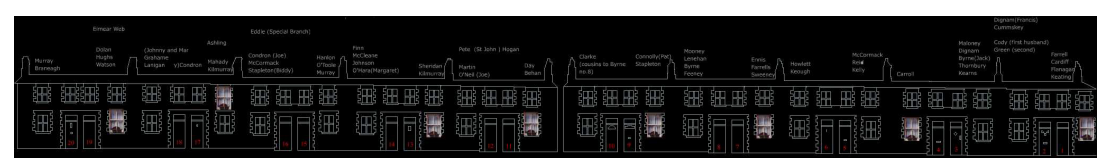

Figure 1. Weird View Graphical User Interface

The Weird View story fragments are organized in a branching structure following two main criteria: the social network and a spatial metaphor. The social network naturally ties together some of the characters that feature in the stories. Members of the same family and friends and neighbors that appear in more than one story are hyperlinked to the other stories in which they feature. The second navigational criterion is the spatial distribution of the stories. The intention is to provide the readers with a map of the story space that illustrates the relation of the content to specific locations. Readers can access stories related to each house by clicking on doors and windows on the drawing. Essentially, each story is a self-contained unit that is independent from the others, but which maintains a link to a specific house and to recurring themes or characters. Due to this modular structure, the reader can end the experience at any time without missing the sense of closure. The cursor is thought of as a probe that allows the reader to knock on doors and windows of the houses, and the act of knocking is used to release the appropriate story fragments. The reader is free to choose whether to follow the textual links that related theme or characters together or continue to explore the houses by knocking on more doors and windows.

\section{Reflections}

A story is an act of interpretation of the world, rooted in the particular perception of the author and aware of the difference between the object of study of the anthropologist and of the narrative critic. There is no mechanical or digital way to substitute this and no reason for wanting to do so (Martin, 1986). In order to exercise her craft, the author must be able to retain control over the many levels of artistic choice. The choices and the interpretation of the story fragments made by the authors of Weird View during the production phase, created a starting point for the people to intervene, remember more anecdotes and criticize the ones already produced. Nevertheless, Weird View artistic reinterpretation of the stories itself raises some interesting issues. During the public exhibition of the piece, questions about the boundaries between public and private came up. The Weird View authors explained intentions and methods to the community during the collection of the content, but many choices still had to 
be made along the way and often with little time or means for consulting or agreeing with community members on all the issues that come up while the work was in progress. In any case, the experiences described above are encouraging preliminary results that motivate further steps in the area of interactive narrative and community's stories.

Ultimately, on the nature of interactive storytelling, and navigable structures, our path through an interactive work reflects our choices back to us, like a mirror, making us more aware of and responsible for our experience (Rokeby, 1995). The Weird View narrative acted as a mirror towards its audience in two different ways. First, it allowed the general public to learn about life in Weir View by exploring the community story collection and choosing their own path through it, leaving with a very personal idea of the community and of the work itself. Second, the audience that belonged to the Weir View community experienced the work literally as a mirror of themselves, against which they could compare, discuss and redesign their past, present and future. In conclusion the Weird View projects set the ground for further artistic explorations in two main directions. On one side, pushing the combination of digital technologies and narrative structures even further, taking advantage of the latest developments, in mobile connected devices, with narratives possibly breaking out of the computer screen, and inhabiting the real world. On the other side continuing the investigation of the power of location, cultural heritage, capturing the grass root spirit of a place by rendering it's more site specific atmospheres through a narrative experience.

\section{Hopstory (2002) - A narrative distributed in space and time}

As computing and communication technologies evolved, the potential for new forms of digitally orchestrated interactive narratives emerged. In this context, Hopstory (Nisi; Wood et al., 2004) was a distributed story incorporating portable wireless technology in the narrative process. The story develops with a linear progression of the plot mapped to real time and unfolding in space using the architectural layout of the building as a navigation tool. Depending on the time and the space the audience is situated in when interacting with the Hopstory, they retrieve parts of the story, relating to different characters points of view. Through physical contact with locally distributed sculptures, the audience collects cinematic scenes for later viewing. Inspired by the history of the installation space the story narrates a day in the life of four characters, focused on their different points of view on the same events, taking place during a single day of work in the installation building, originally a brewery. An additional character with a different role to play, a cynical brewery cat, wan- 
ders around the story providing historical anecdotes in what we called ambient scenes where no human character appears.

Hopstory is novel in the way in which it chains physical navigation through the installation with character point of view. As Rokeby points out the story space can be conceived as a navigable structure or world (Rokeby, 1995). In the case of the Hopstory the architectural metaphor can be taken literally. Furthermore, the story connects to the audience's sense of time. As the story progresses, the characters move through the building, living out their day in the early 1900s. Similarly, as the audience wanders through the same building, experiencing the installation, they encounter the four characters at different locations and times. Moreover, the audience encounters sculptures modeled after a brewery cat, a special character in the story. The sculptures indicate the locations where the story content is available. Using a simple RFID enabled object for interacting with the sculptures the audience is able to collect scenes. When a scene is collected, an audio segment from that scene is played. Essentially, through contact with a cat, a participant receives a new scene and uncovers a character, who responds orally by revealing a part of his or her story. The instantaneous audio response may encourage audience members to seek out more scenes to add to their collection. The audience controls the number of clips they collect but do not know what events they will witness before they make contact with a sculpture. Much like wandering through an actual building and choosing to eavesdrop on chance conversations, audience members edit their own movies by navigating the building space. However, rather than viewing each scene at the moment it is encountered, the audience saves up their collections for later viewing, allowing interaction with the system while carrying out other tasks and experiencing the movie when it is convenient. We found that the location-focused nature of the story provided a creative playing field for developing content. In the case of our installation (see Fig. 2), designed to be housed within a culturally significant brewery building, the historical inspiration was natural. Access to the physical setting of the characters' lives provided a concrete starting point for research, visualization of scene description, and conception of plot events.

\section{Reflections}

Hopstory was exhibited at MediaLab Europe in 2002. The events attracted a large and diverse group of academics and corporate representatives to the facilities. The audience was interested and curious about the distributed structure of the narrative; they appeared to find the concept of a location based narrative fascinating. The audience also responded well to the physical form 


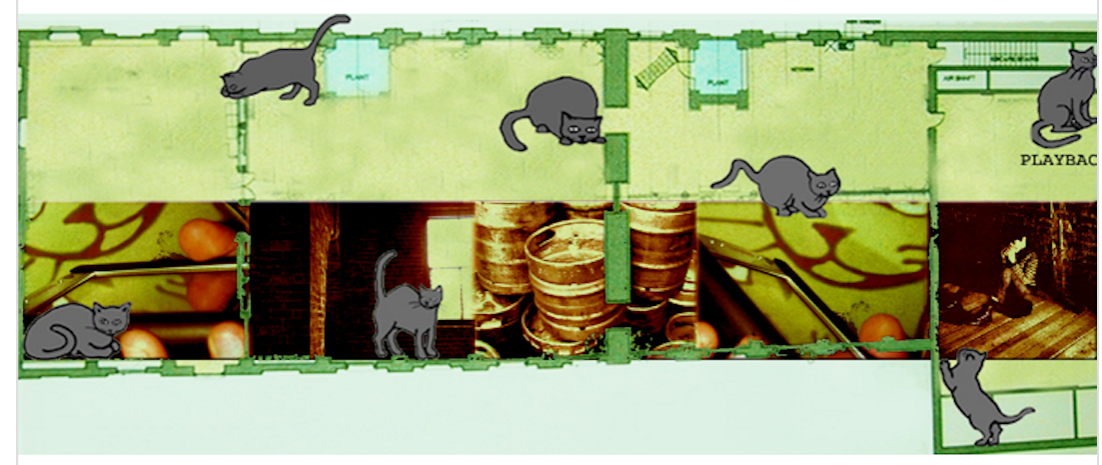

Figure 2. Hopstory installation

of the sculptures, finding them appealing. The separation of story navigation and story viewing provoked mixed response among the users. While some had difficulty relating the collected fragments to the experience, others reported a relaxed experience. They pointed out that not having to stop and view the story at every node created a less disruptive experience that contributed to a more coherent plot. Many visitors, whose main objective was to visit the lab facilities, kept the RFID objects with them and collected story fragments when they casually happened upon a cat sculpture. When these visitors came to the playback area to cash in on their story, we usually had to refresh their understanding of how the experience worked. Other visitors focused fully on the Hopstory installation, actively searching for all the cats. These visitors collected story segments rapidly and then came to the playback area to review the story they had collected while navigating the floor. Few wanted to go back and experience more stories because they were aware the story was unfolding in real time. Finally, the visitors passing by the playback area usually stopped and watched movies that others had collected and were curious to know more about the project. An advantage of using RFID objects for interaction with Hopstory was the non-intrusive quality of this technology. They could remain in a bag or pocket, easily accessed if a participant chose to engage with Hopstory.

The Hopstory experience has inspired new research directions within the form of physically distributed interactive storytelling. The idea of linking a story to place can be taken further. The story content could be rigorously mapped to specific location-while the scenes in the movie could depict the exact spots where the story fragments are available, creating surprising "magic 
moments" effects (Reid et al., 2005). The sculptural objects could also be enhanced to reflect story content, taking the physical form of objects or events in the narrative. The Hopstory installation had been an exciting step forward in developing new forms of computational interactive narrative, which weds story content organically with enabling technology.

Media Portrait of the Liberties (2004), Trading Mercator Stories (2006) and Placewear (2006) - Locative Media at the service of disadvantaged neighborhoods

The Media Portrait of the Liberties (MPL), Trading Mercator Stories (TMS) and Placewear (PW) are three different hands-on investigation of site specific forms of narrative that makes extensive use of mobile location aware computing technology and multimedia. Multimedia content is superimposed on a map based Graphical User Interface and rely on GPS sensing for location awareness (see Fig. 3). Such projects were designed to make stories, in form of short multimedia video, available to viewers at particular geographical locations and thereby contribute to a community-related story map of the area.

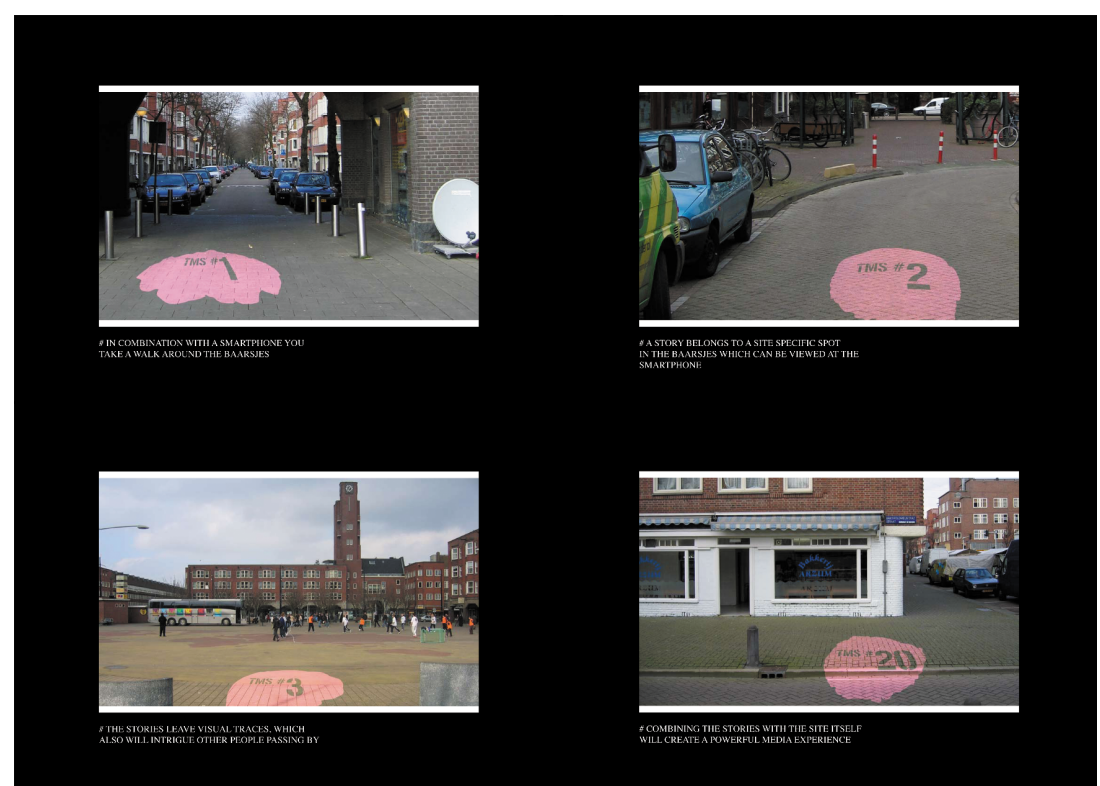

Figure 3. Trading Mercator Stories

The MPL is a collection of historically inspired video stories mostly adapted from Maireen Johnston written accounts of life in the "Liberties" a depri- 
ved but culturally cohesive inner city area of Dublin, Ireland (Nisi \& Oakley, 2006). The project completion dates back to 2004 when location-aware adapted Personal Digital Assistants (PDA) were the latest technologies in terms of mobile devices. The narrative collection was designed so that each story fragment could only be viewed when an audience member is situated in the physical place where the story once happened. Several years later, in 2007, invited by the Dutch government through the Digital Pioneer initiative ${ }^{3}$ we produced Trading Mercator Stories (Valentina Nisi et al., n.d.), in order to offer "a sense of place" of the Amsterdam's multicultural and disadvantaged neighborhood of the Baarsjes. This area is home to a diverse contemporary community made of immigrants from different countries such as Turkey, Morocco, Indonesia, Suriname to name a few, as well as a broader base of Amsterdam residents. The area is also visited by occasional tourists due to its special Architecture style ${ }^{4}$ and variety of food shops and restaurants that map out the wide variety of nationalities inhabiting the neighborhood.

Similarly, Placewear, commissioned by imagine IC, a Beijmermeer based community heritage focused agency, was designed with the intention of stimulating visitors awareness of the social cohesion and cultural qualities of the Beijlmermeer neighborhood. Stories were collected locally and produced in cooperation with community members themselves and local published writer Pierre Heijbor. The stories disclose a lively and proud community that defeated disadvantaged and segregated conditions by becoming a strong and culturally rich neighborhood. Bijlmer, is one of the neighborhoods that form Amsterdam-Sud. Following the Suriname independence in 1975 many immigrants of Suriname were placed in social housing in the Beijlmer. The neighborhood had a relatively high crime rate but this has decreased dramatically in the recent years, while his reputation with the general public still remained somehow disadvantaged.

The common objective of these three projects is to provide its audiences with a nuanced and evocative sense of place as they walk the streets of these striking neighborhoods. The projects approach to community stories is designed as a layer of content superimposed to the physical space, presenting visitors with grass root community accounts in stark contrast with the portrait offered by the mainstream media. The approach proposes an inspiring starting point for the locals to take ownership of their history and possibly continue to feed the projects collection of stories. Despite the intention this final stage was never implemented due to lack of funding.

3. www.kl.nl/en/cases/digitale-pioniers/

4. The Amsterdam School style of architecture (1915-1940). 
A multidisciplinary team of several people worked on each of the projects, researching social issues, making contact with the local community and its organizations, developing software and interaction design, scripting and producing the video story segments. The methodology for all three projects was largely based on the Media Portrait of the Liberties (Nisi; Oakley \& Haahr, 2008). Nevertheless, TMS and PW took advantage of the MPL guidelines and evolved in terms of methodology and technology used. Firstly, TMS and PW made use of more advanced technologies, instead of the GPS equipped PDA, they were able to use smartphones with integrated GPS modules, much easier to acquire and to use. Also the content production models were slightly different for all three projects. On the one hand, they all involved a series of local stakeholders, but while for MPL the author retained control over the selection and production of the video stories, for TMS and PW story collection and production was based on seminars and workshops conducted by the authors with the local community members. Local adults and children were coached and tutored into the production of their own short stories. Another method, utilized by MPL as well as PW, involved a close relationship with a local writer, who provided content about the community mainly form her or his published work and helped with the scripting of the narrative fragments. Maireen Johnston for the Liberties Portrait and Pierre Heijbour for the Beijlmermeer helped selecting story fragments from their published work and adapted it for the mobile screen. On the other hand, local organizations such as the Mercator's local library and Imagine IC agency were deeply involved in embedding the projects in the local fabric, supporting participation in art festivals and providing visibility and publicity during the whole initiative and even some time after the project was concluded and funding were finished.

\section{Reflections}

Interactive Location Aware Multimedia Stories (LAMS) are an ambitious interactive art form, combining narrative, visual art and interactivity. It utilizes site specific stories to design transformational experiences that convey the atmosphere and grassroots history of local communities influencing the audience perspective on the neighborhood. To fulfill the interactive narrative properties of the project, each story is available to the public in the specific location where it happened. The areas became a geographical tableau of stories where the audience can physically navigate the narrative by walking the streets of the neighborhood.

Similarly to what we noticed happening with Weird View, the audience is left transformed by the experience. This transformation results from the ope- 
ning of new perspectives on the neighborhood for visitors and locals as well. The mechanics of the projects enable the local community to witness their reality reflected back on themselves highlighting the mundane and every day. Unfortunately, we were not able to conduct formal studies about the quantity and quality of these transformations. On the other hand, we were able to collect qualitative feedback from audience members, in the form of post experience comments made directly to us or to the local supporting staff, which was often asked to extend or replicate the projects public exhibition periods. Moreover, audience members volunteered a range of suggestions from recommendations for the interface design, such as the need of guided paths for nonresidents to extending the project to include the possibility of adding their own stories after experiencing the project. The Liberties local agency Digital Hub, the Mercator library and Imagine IC all expressed interest in purchasing several devices in order to keep the project available to the public indefinitely. While Imagine IC did purchase ten devices for them to keep onsite and keep the project alive, for the Mercator Library funds did not free up for such purchase and the project was available only for several months during the summer 2007, when we were able to lend two mobile devices for them to keep at their desk. Regarding the MPL we left the original PDA and GPS module available for the public at the local Digital Hub office, situated in the heart of the Liberties. Unfortunately, the technology was quickly outdated and since the research project was concluded and the research team moved on and out of Dublin, we were not able to transfer the software and content to more updated devices for them to use. Moreover, retrospectively analyzing the project's conception, we noticed that there was a crucial strategic missing step. All three projects, did not originate from an uncovered need or desire of the local community. Although the Media Portrait of the Liberties concept was successful in Dublin, it was produced and conceived as a research project rather than a community project. Similarly, in both the other case, the projects were funded before research on how to contextualize them could be conducted. In fact, despite the successful completion of the projects as a LAMS transformational experiences, we observed the lack of opportunity for the projects to remain alive when the initial funding run out. However, the involvement of local stakeholders early in the story production process for both TMS and PW was one main successes and innovation in our strategy from the early MPL version. We like to reflect on this issue by highlighting the benefits of early use of ethnographic methods and field research before the creative concept is fully formed. This approach can reveal opportunities for design and innovation in LAMS projects. The discovery of such 
opportunities might even contribute to the overall sustainability of the LAMS as a service

\section{Stories (2011-2015) - From urban computing to location based services}

By the end of the first decade of the year 2000, smart, mobile and context aware became the norm for mobile phone users. In particular with the booming of location based services, in the context of highly touristic places, we saw an opportunity to design a location-based experience focused on a touristic destination local culture. 7 Stories is a mobile application, which treasures traditional folklore and makes it available mostly to foreign residents and tourists of the city of Funchal, in Madeira Islands. The first outpost of the Portuguese discoveries, Madeira Island is rich in history and traditions, superstitions and folktales. A well-known European touristic destination, the island is visited monthly by thousands of tourists who are not aware of its lore, albeit when offered information they are very interested in further investigation (Dionisio, Nisi, \& Van Leeuwen, 2010). 7 Stories capture some the Madeiran most traditional folktales often collected by word of mouth, and functions as a repository of local culture against memory erosion. To offer a contained experience in a traditional setting, easy to navigate by non-local people, we chose to set the experience in Rua Santa Maria, a long and narrow street located in the old town which still maintains its traditional atmosphere. Old anecdotes and folktales from the local tradition were researched and collected to serve as the content for the narrative experience. In order to create a connected journey through the narratives, the adaptation also emphasized links between the different story fragments. The video material was produced with amateur actors and film crew and took approximately four weeks to complete, including the final editing time. Seven short video-based stories were completed, with a duration ranging from one to three minutes each. The audiovisual medium was chosen because it allowed us to render the traditional story plots, and complement them with further local traditional elements such as costumes, used objects and typical locations, such as interiors of houses and courtyards, embroidery practices, the local countryside, traditional milk cans and so on. 


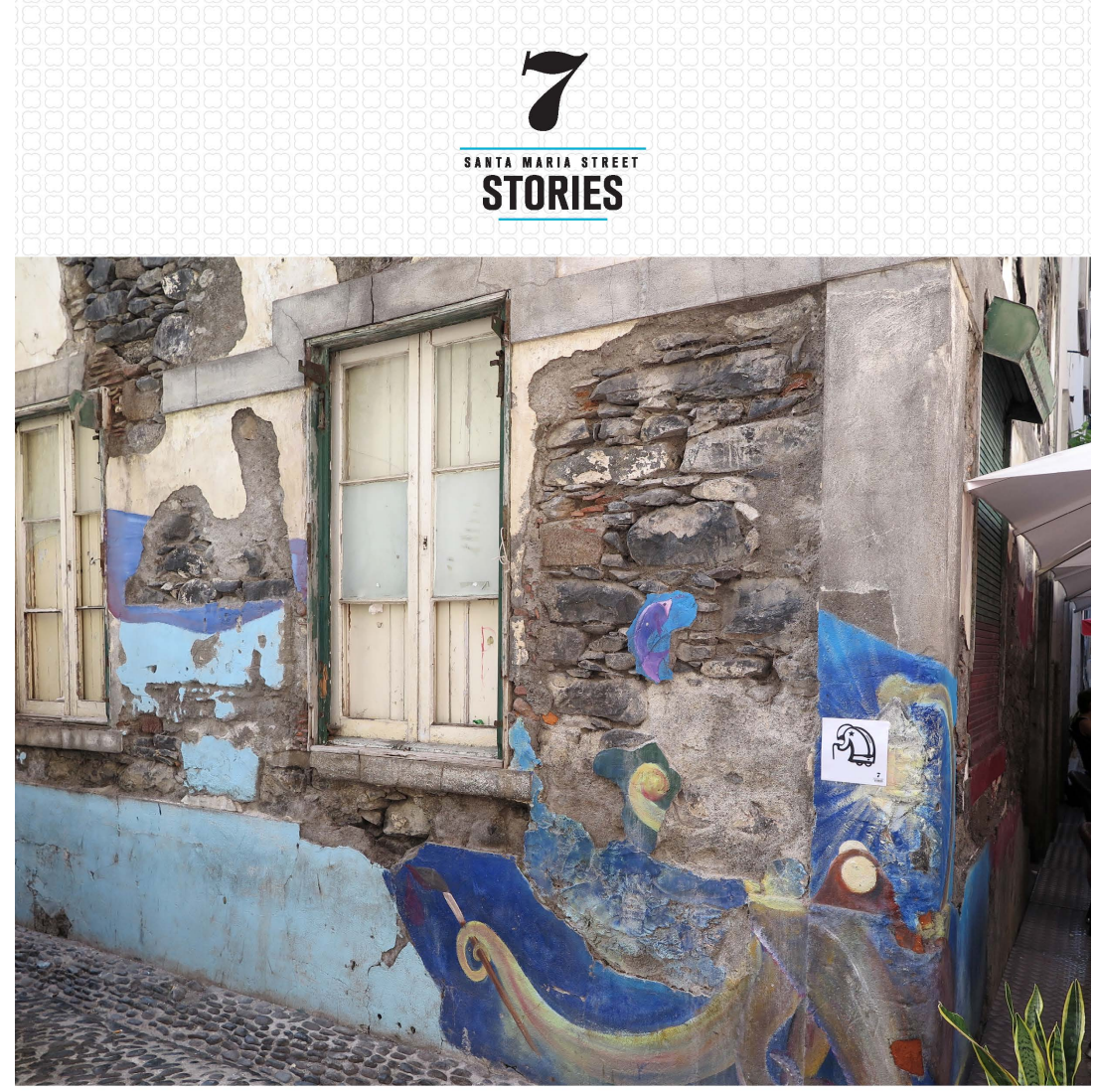

Witch
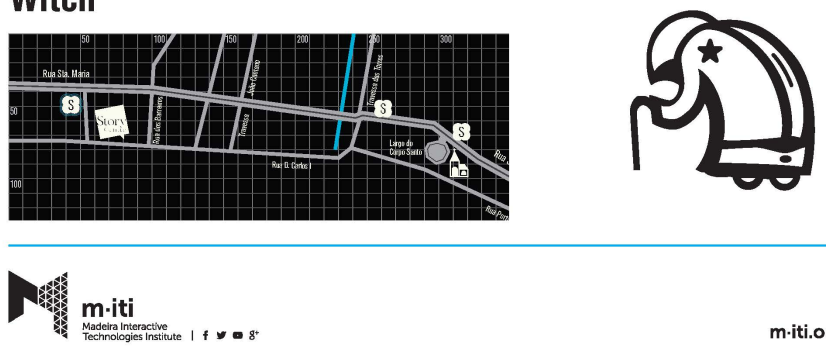

m.iti.org

Figure 4. 7 Stories

All the stories have strong links to the locations in which the audience is able to retrieve them. Connections are made in particular through the visuals of the video material. For example, for the story where a Santo Antonio statue is thrown from the window of a balcony, the real window and balcony in the 
street are referenced by the narrator during the recounting of the story, thus functioning as an anchor point in the setting where the audience experiences it. Technically, the 7 Stories application is available for all main Android platforms. 7 Stories maintains all the content offline, translates the user position from the GPS coordinates into pixel coordinates displaying the user position as an icon on the graphic interface so that the application can work without internet connection. When a user is in range of a story the phone vibrates and an audio clip with the narrator's prelude is automatically triggered. The narrator is kept in audio format to limit the demand for visual attention to the device screen, especially since the narrator himself would verbally describe and point at features in the real environment to help users orient themselves and find the next piece of content. Moreover, once the narrator has greeted the audience and pointed them in the right direction where to find story content, the system works so that the story video clips are triggered by scanning visual markers through the smartphone camera, rather than by pressing a GUI button on the phone's screen (see Fig. 4). The d-touch markers technology (Costanza \& Huang, 2009) allowed us to design our own visually and semantically meaningful markers, (see, for example, Fig. 4). Markers were then distributed along the street where the stories were designed to be viewed. Moreover, the markers are very inexpensive and easy to print, making it uncomplicated to replace them in case of damage.

\section{Reflections}

As another interactive story conceived as a research project, 7 Stories was evaluated in depth, which allowed us to confidently asses that the overall the experience was largely successful. We observed that participants, engaged in the experience, were appreciating the guiding function of the narrator and considering the markers as a tangible feedback and reward. No feelings of being overwhelmed or lost were reported. In particular, the integration of the narrator and the visual markers as a support to the GPS position system seems critical for making the experience overall successful. The adoption of d-touch markers adequately compensated for GPS glitches: seeing the markers provides users clear, tangible feedback that they are in the right place. The markers demonstrated to have the potential to balance between the physical and digital elements of the experience. Markers highlight details of the physical space, before audiovisual clips are played. Using a narrator seems to support users in the exploration of the narrative space and physical environment, and helped in delivering a more satisfying and contextualized location-based experience to our audience. Building on the analysis of the user studies, we have highlighted 
general guidelines and implications for the future of the design of locationbased narrative systems. In particular, we highlight the importance of a careful design for balanced and fluid user transitions from digital content to the physical aspects of the experience, and how technological (GPS and markers) as well as narrative (the use of a narrator device) design solutions can help with this. We hope that reporting on our experience and findings will help others in designing successful location-based applications and cultural storytelling experiences and, in general, encourage the both communities of artists and researchers in interactive narrative systems to conduct comparative evaluations of the specific features of such systems in order to learn, improve and innovate in the field.

\section{Yasmine (2015) - Immersive storytelling and urban computing}

Yasmine's Adventures (YA), is a LAMS based interactive story that leverages on immersive media and urban computing strategies to create an interactive trail across the Mehringplatz landscape surrounding the Jewish Museum in Berlin. YA was created with the goal of engaging visitors of the museum to explore the adjacent and relatively neglected streets of the area in which it is situated. In our previous work we experienced that the conscious layering of space and narrative provides a compelling, immersive experience with the power to reveal a community that is often overlooked. Through YA the audience follows the adventures of a free-spirited local girl named Yasmine as she sneaks away from her class field trip to the museum and attempts to walk home alone. The story is delivered through a mobile application that combines the capturing of visual cues around the neighborhood with the delivery of a sequence of short animations tailored specifically to the Mehringplatz area. The YA project was developed as part of the Community Now! Research project and Symposium in order to investigate how a location aware and immersive media can impact the audience perception of a neighborhood. Previous to the project, the Community Now! research team worked closely with the local community collecting impressions, desired and issues regarding the Mehringplatz neighborhood. This material then served as a basis to construct the narrative sequences. In fact, Yasmine's perceptions of the area reflect the real concerns of the community. 


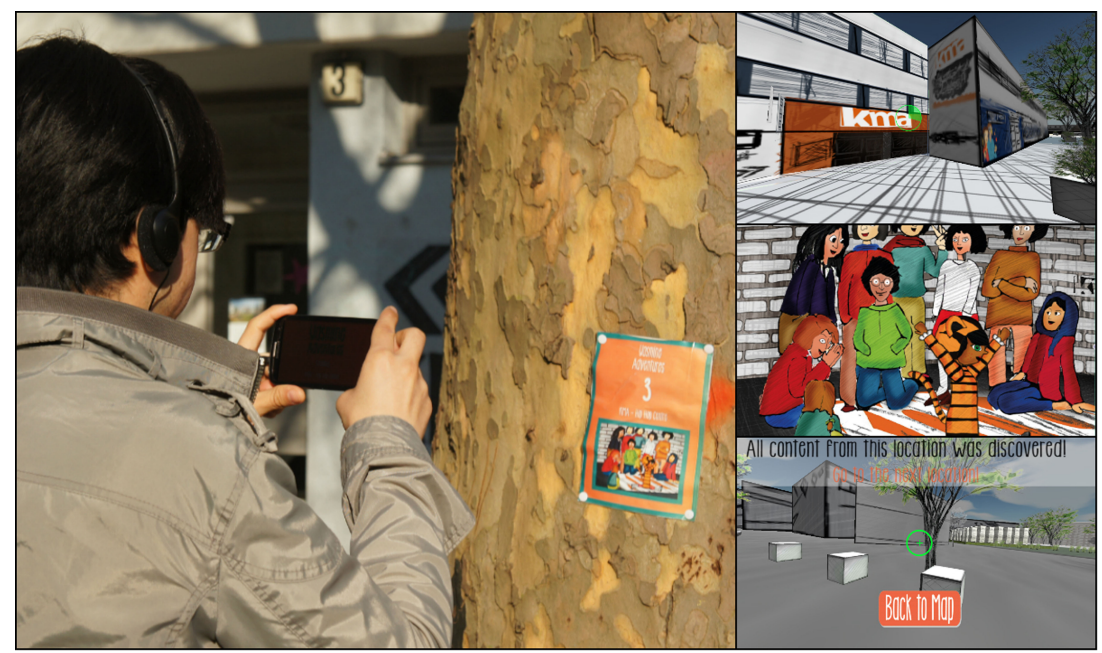

Figure 5. Yasmine Adventures

Yasmine has positive experiences in the locations appreciated by the community, while she experiences fear, and discomfort where the community expressed negative appreciation of the locale. The experience was initially designed as if it were a service provided by the Jewish Museum to its visitors. Museum visitors are given a YA enabled phone and after a short introductory video they are instructed to exit the museum and look for visual markers located in strategic spots. The markers are A5 postcards depicting scenes from YA (see Fig. 5). By pointing the phone's camera and capturing the marker, a 3D 360 degrees' reconstruction of the surrounding environment is displayed on the screen and the user is prompted to scan the virtual environment looking for story content by moving the mobile phone around the physical space. Once found, the video animation is loaded and the user can watch it. The animation depicts an adventure of Yasmine in that specific location. When the video clip ends, the user returns to the 3D environment screen by clicking a back button, and can scan the virtual environment for more stories. If no other stories are available, the user is prompted to go back to the 2D map and follow the indications of where to find more content. The story fragments are sequential so the locations must be visited in the correct order. Yasmine's story ends with a concluding video after all five locations highlighted on the map have been visited. The walk lasts approximately $20 \mathrm{~min}$. The project was evaluated on site through a pilot study and a full user study with more than 20 users. Results from the qualitative and quantitative evaluation of YA user's experience suggest that connection and perception to a location changes when locative media 
narratives include learning, understanding and discovery elements. We report highlights form the study below.

\section{Reflections}

From the results and the analysis of the YA evaluation, we found YA to promote relatedness and exploration of the local neighborhood. Participants mentioned feeling absorbed in the story content, wishing to have extra visual markers and further information as they explored the space. The results indicate that participants did experience a sense of presence generated by the LAMS and this feeling allowed them to be immersed in the story. The sense of presence in the story enabled users to gain a greater awareness of the neighborhood's physical space but also of the people living in it. This awareness expanded to feeling empathy and a shared understanding for community issues, since the story exposed issues identified by community members themselves. Examples of participant engagement were the attention to and the awareness of the surrounding space throughout the experience, and the reported desire to consume more complex content, visual clues and information, to learn more facts and expand the tour. Moreover, audience members often expressed the desire to talk and interact with community members during the tour and manifested the desire to learn more facts, testimonials form the locals themselves. We deduce that LAMS with a sociocultural intent should include even more factual information about the neighborhood to generate a stronger connection between the audience and the local community. In summary, the findings uncovered through the YA user study suggest that locative media associated with story content is a successful strategy for generating engagement and connection to local communities. However, these digitally mediated sociocultural efforts, need to go beyond the individual engagement of a few people and perhaps even expand over longer periods of time. Users suggested that looking at historical facts from a community perspective and adding testimonials from the local inhabitants that allow others to understand the cultural and physical evolution of a particular location, would be a very welcome feature in LAMS. Learning by being in the place, discovering and connecting factual elements with the real location, and ideally having direct contact with community members, seem to be key elements for the successful engagement of visitors in the discovery of socially marginalized, overlooked, or underprivileged neighborhoods. 


\section{Echoes of Nature and Fragments of Laura (2014-ongoing) - Transmedia at the service of Natural Capital}

With the increasing importance of interaction for sustainability, new opportunities for designing meaningful interactive narrative interventions are continuously emerging. Started back in 2014, from the Future Fabulators ${ }^{5}$ Culture Europe project, Echoes of Nature investigates how storytelling, coupled with mobile interactive and transmedia technologies, can be used to design interventions that bring awareness and engage people in understanding the benefits of the local Natural Capital, its ecosystems and their underlying biodiversity. This work was conceived as a way of inviting visitors to the island of Madeira in valuing the local natural resources through transmedia storytelling. As mentioned before, transmedia storytelling is a technique of providing a story experience across multiple platforms and formats. Following this approach, the Echoes takes shape through two different interdependent channels. On one side a location aware fictional mobile story: Fragments of Laura (FoL). Using real historical events as the background, the story develops as a location based playable story, where, as Ryan's describes it; the user actions are subordinate to the narrative meaning (Ryan, 2009). FoL engages its audience in exploring les known areas of the city of Funchal and learning about its history and the island natural capital wealth. The audience follows the adventures of Laura, a local heroine, who acted as a proto pharmacist in the early 1800 . On the other side, the "Echoes of Nature" platform, designed to complement FoL, connects Portuguese and foreign visitors - with local scientists, traditions, and day to day events that happen on the island. Drawing on principles of community journalism, our goal is to make Echoes of Nature participatory by encouraging users to view its content and inviting the public to send questions, comments, or user-generated content (such as photos, videos, or posts. At the same time shorter teasers related to relevant themes are to appear at the end of each fictional episode on the mobile FoL app (see Fig. 6).

5. http://futurefabulators.m-iti.org/ 
The changing panorama of interactive storytelling: a review from locative to

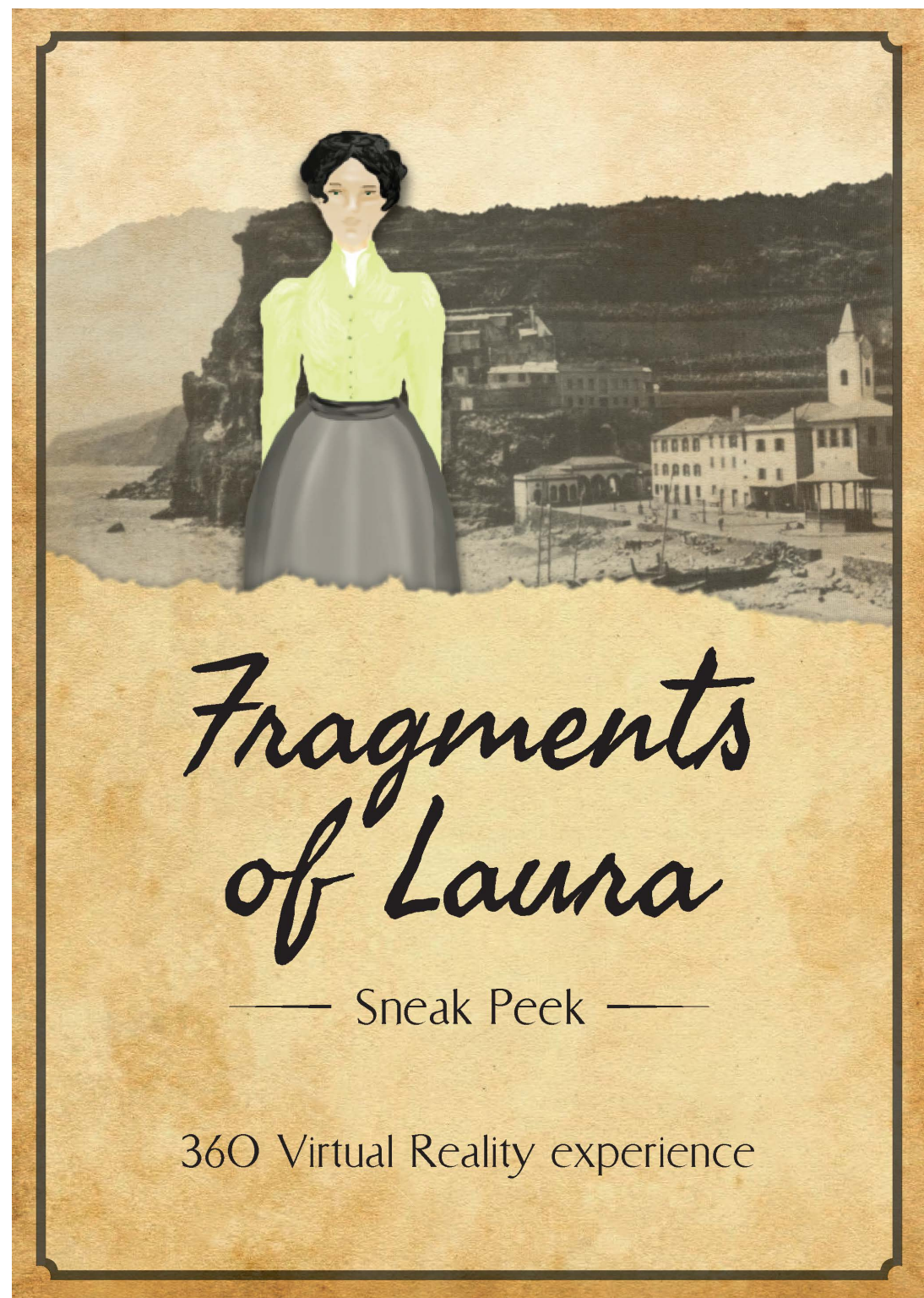

Figure 6. Echoes of Nature and Fragments of Laura 


\section{Reflections}

The originality of the project resides on the exploratory approach of intersecting a fictional transmedia storytelling with journalistic style interviews woven together towards the common goal of fostering environmental preservation on a small island. The focus on a fictional character allows for the interweaving of varied facts (cultural, historical and scientific) that would be difficult to incorporate if not for the liberty that fictional writing affords. Through our transmedia experience, visitors to Madeira will embark on a quest to find the ancient book of knowledge and its author, Laura. The mobile platform (due to its positioning service) will play a crucial role in the experience in helping tourists to discover the story locations. It will serve to display rich media content that allows the recreation of the 19th century way of life including architectural features, clothing and behavior. The web features on the other hand, will connect fiction with the reality of the natural capital of the island, its community of scientist and naturalists, through a growing repository of video interviews and podcasts. The project is now on its second prototyping stage. The prototype is being tested and refined as we speak. Finally, both Fragments of Laura and Echoes of the Nature are part of the ongoing Beanstalk research project.

\section{Conclusions}

The trajectory highlighted in this text highlights how mobile interactive devices changed the panorama of interactive storytelling in the past 20 years. The notion of Location Based Multimedia Stories emerged, braking out from the desktop and moving into in to the real world.

The first project, Weird View, a site specific hypermedia interactive narrative attempts to capture community folklore and represent it in the form of an interactive, nonlinear narrative. The Weird View story is organized in a branching structure following two main criteria: the social network and a spatial metaphor. The project raised interesting issues, in particular questions about the boundaries between public and private, memory recollection and preservation.

In the second project, Hopstory, the story develops with a linear, plot, progressing in real time and unfolding in space, using the architectural layout of a building as a navigation tool. In Hopstory the architectural metaphor is taken literally, providing a navigable structure through the articulation of space, real, virtual or conceptual. The Hopstory experience inspired new research directions within the form of physically distributed interactive storytelling. Media Portrait of the Liberties, Trading Mercator Stories and Placewear are three 
successive projects which make use of site specific narrative, mobile location aware computing and multimedia content. The common objective of these projects is to provide its audiences with a nuanced and evocative sense of place as they walk the streets of neighborhoods. The projects approach to community stories is designed as a layer of content superimposed to the physical space. The intervention areas become a geographical tableau of stories presenting visitors with grass root community accounts in stark contrast with the portrait offered by the mainstream media.

The experimental nature of the previous projects was taken further with the ubiquity of location-aware mobile devices. In two projects (7 Stories and Yasmine Adventures) an Android platform deploys new location-based experiences focused on touristic destinations and local culture. Proper research on the use of these systems provides a framework to encourage the both communities of artists and researchers to conduct comparative evaluations of the specific features of such systems in order to learn, improve and innovate in the field.

Finally Echoes of Nature explores how LAMS can lead to transmedia design interventions that bring awareness and engage people in understanding more complex issues such as the benefits of the local Natural Capital, its ecosystems and their underlying biodiversity. In this project we are intersecting a fictional transmedia storytelling with journalistic style interviews allowing for the interweaving of varied facts that could foster sustainable tourism and environmental preservation on a Touristic Island destination.

The art of storytelling is a fundamental need of human society. Thanks to the advances in digital media technology, cheaper creative tools, agile production processes and novel and wider distribution channels, the narrative panorama is continuously challenged. Nevertheless, old storytelling crafts are not dying, but merely evolving, expanding, integrating new technologies, taking up new challenges, changing the way we see and relate to the world. Yielding new opportunities to the contemporary generations of storytellers.

\section{Bibliographic references}

Aarseth, E. J. (1997). Cybertext: perspectives on ergodic literature. Johns Hopkins University Press.

Alexander, B. \& Levine, A. (2008). Web 2.0: digital storytelling. Liberal Education, (december 2008), 11.

Angus, A.; Papadogkonas, D.; Papamarkos, G.; Roussos, G.; Lane, G., \& et al. (2008). Urban Social Tapestries. IEEE Pervasive Computing, 7 (4): 44-51. https://doi.org/10.1109/MPRV.2008.84 
Arfman, J. \& Roden, P. (1992). Project Athena, Supporting distributed Computing at MIT, IBM. Systems Journal, 31 (3): 550-563.

Bell, M.; Chalmers, M.; Barkhuus, L.; Hall, M.; Sherwood, S.; et al. (2006). Interweaving mobile games with everyday life. Proceedings of the SIGCHI Conference on Human Factors in Computing Systems (pp. 417-426). New York, NY, USA: ACM. https://doi.org/10.1145/1124772.1124835

Benford, S.; Anastasi, R.; Flintham, M.; Drozd, A.; Crabtree, A.; Tandavanitj, N. \& Adams, M. (2003). D E A L I N G W I T H U N C E R TA I N T Y Coping with Uncertainty. Online.

Bizzocchi, J. \& Woodbury, R. F. (2003). A case study in the design of interactive narrative: the subversion of the interface. Simulation and Gaming, 34 (4): 550-568. https://doi.org/10.1177/1046878103258204

Cater, K.; Fleuriot, C.; Hull, R. \& Reid, J. (2005). Experience design guidelines for creating situated mediascapes. Retrieved from www.cs.bris.ac.uk/ Publications/Papers/2000510.pdf

Chalmers, M. \& Galani, A. (2004). Seamful interweaving. Proceedings of the 2004 conference on Designing interactive systems processes, practices, methods, and techniques - DIS '04 (p. 243). New York, New York, USA: ACM Press. https://doi.org/10.1145/1013115.1013149

Costanza, E. \& Huang, J. (2009). Designable visual markers. Proceedings of the 27th international conference on Human factors in computing systems - CHI 09 (p. 1879). New York, New York, USA: ACM Press. https://doi.org/10.1145/1518701.1518990

Crabtree, A.; Tandavanitj, N.; Steed, A.; Benford, S.; Rodden, T. et al. (2004). Orchestrating a mixed reality game "on the ground". Proceedings of the 2004 conference on Human factors in computing systems - CHI '04 (pp. 391-398). New York, New York, USA: ACM Press. https://doi.org/10.114 $5 / 985692.985742$

Dionisio, M.; Nisi, V. \& Van Leeuwen, J. P. (2010). The iLand of madeira location aware multimedia stories. Lecture Notes in Computer Science (including subseries Lecture Notes in Artificial Intelligence and Lecture Notes in Bioinformatics) (vol. 6432 LNCS, pp. 147-152).

Falk, J.; Ljungstrand, P.; Björk, S. \& Hansson, R. (2001). Pirates. CHI 'OI extended abstracts on Human factors in computing systems - CHI 'O1 (p. 119). New York, New York, USA: ACM Press. https://doi.org/10.1145/63 4067.634140 
FitzGerald, E.; Taylor, C. \& Craven, M. (2013). To the Castle! A comparison of two audio guides to enable public discovery of historical events. Personal and Ubiquitous Computing, 17 (4): 749-760. https://doi.org/10.1007/ s00779-012-0624-0

Lynch, K. (1960). The image of the city. MIT Press.

Madej, K. \& Krystina. (2003). Towards digital narrative for children. Computers in Entertainment, 1 (1): 12. https://doi.org/10.1145/950566.950585

Ryan, M.-L. (2009). From narrative games to playable stories: toward a poetics of interactive narrative. StoryWorlds: A Journal of Narrative Studies, 1 (1): 43-59. https://doi.org/10.1353/stw.0.0003

Martin, W. (1986). Recent theories of narrative. (Cornell University Press, Ed.).

Morelli, N. \& Tollestrup, C. (2006). New representation techniques for designing in a systemic perspective: educating designers. Design Society.

Nisi, V.; Oakley, I. \& Haahr, M. (2008). Places, location-aware multimedia stories: turning spaces into places. Artech, INternational Conference on Digital Arts: 72-82. Retrieved from http://artes.ucp.pt/artech2008/

Nisi, V. \& Haahr, M. (2006). Weird view: interactive multilinear narratives and real-life community stories. Crossings, 1 (1): 1-7. Retrieved from http://mf.media.mit.edu/pubs/journal/WeirdView.pdf

Nisi, V. \& Oakley, I. (2006). Inner city locative media: design and experience of a location-aware mobile narrative for the Dublin Liberties Neighborhood. Intelligent Agent. Retrieved from http://mf.media.mit.edu/pubs/ journal/InnerCity.pdf

Nisi, V.; Oakley, I. \& M. de Boer, P. (2010). Locative narratives as experience: a new perspective on location aware multimedia stories. ArTech 2010. Porto.

Nisi, V.; Wood, A.; Davenport, G. \& Doyle, L. (2004). Hopstory. Proceedings of Second International Conference, TIDSE 2004, 24: 132-141.

Paay, J.; Kjeldskov, J.; Christensen, A.; Ibsen, A.; Jensen, D.; Nielsen, G. \& Vutborg, R. (2008). Location-based storytelling in the urban environment (p. 122). ACM Press. https://doi.org/10.1145/1517744.1517786

Polak, E. (2002). Mental map / Real map. Amsterdam: email of the author to friends.

Reid, J.; Hull, R.; Cater, K. \& Fleuriot, C. (2005). Magic moments in situated mediascapes. Proceedings of the 2005 ACM SIGCHI International Conference on Advances in computer entertainment technology 
- ACE 'O5 (pp. 290-293). New York, New York, USA: ACM Press. https://doi.org/10.1145/1178477.1178529

Rokeby, D. (1995). Transforming mirrors: subjectivity and control in interactive media.

Ryman, G. (1996). 253 - Interactive novel home. Retrieved October 26th 2016, from www.ryman-novel.com/

Slaney, M. (2012). Tell me a story. IEEE Computer: 4-6.

Smith, J. (2000). GrandChair: conversational collection of grandparents' stories.

Souza e Silva, A. de (2006). From cyber to hybrid: mobile technologies as interfaces of hybrid spaces. Space and Culture, 9 (3): 261-278. https://doi.o $\mathrm{rg} / 10.1177 / 1206331206289022$

Spanoudakis, M.; Nakou, A.; Meliadou, E.; Gouscos, D. \& Meimaris, M. (2015). Digital words of wisdom? Milia (AppleTree), an online platform for digital storytelling. Cultural Science Journal, 8 (2): 106-130.

Stevens, Q. (2007). The ludic city: exploring the potential of public spaces. Routledge.

Zheng, Y.; Capra, L.; Wolfson, O. \& Yang, H. (2014). Urban computing: concepts, methodologies, and applications. ACM Transactions on Intelligent Systems and Technology, 5 (3): 1-55. https://doi.org/10.1145/2629592 